Please do not remove this page

RMIT

UNIVERSITY

\title{
Establishing the structure of police evidentiary interviews with suspects
}

Heydon, Georgina

https://researchrepository.rmit.edu.au/esploro/outputs/9921857854801341/filesAndLinks?institution=61RMIT_INST\&index=null

Heydon, G. (2004). Establishing the structure of police evidentiary interviews with suspects. The International Journal of Speech, Language and the Law: Forensic Linguistics, 11(1), 27-49.

https://doi.org/10.1558/sll.2004.11.1.27

Document Version: Accepted Manuscript

Published Version: https://doi.org/10.1558/sll.2004.11.1.27

Repository homepage: https://researchrepository.rmit.edu.au

(c) University of Birmingham Press 2004

Downloaded On 2023/04/26 21:33:03 +1000

Please do not remove this page 
Thank you for downloading this document from the RMIT Research Repository.

The RMIT Research Repository is an open access database showcasing the research outputs of RMIT University researchers.

RMIT Research Repository: http://researchbank.rmit.edu.au/

\section{Citation:}

Heydon, G 2004, 'Establishing the structure of police evidentiary interviews with suspects', The International Journal of Speech, Language and the Law: Forensic Linguistics, vol. 11, no. 1, pp. 27-49.

See this record in the RMIT Research Repository at:

https://researchbank.rmit.edu.au/view/rmit:17773

Version: Accepted Manuscript

Copyright Statement:

(C) University of Birmingham Press 2004

\section{Link to Published Version:}

http://dx.doi.org/10.1558/sll.2004.11.1.27 


\title{
Establishing the structure of police evidentiary interviews with suspects
}

\section{Georgina Heydon}

\section{Manuscript accepted by}

\section{The International Journal of Speech, Language and the Law}

\begin{abstract}
This paper provides a description of the structure of police interviews which aligns the institutionally defined (functional) parts of the interview with a linguistic description meaningful to the analysis of talk in interaction. The analysis is based on data drawn from recordings of police interviews with suspects from rural Australia. It is found that, in particular, the shift from the formal introductory part of the interview to the information seeking part of the interview is marked by participants with an attempt to realign the participant roles (Goffman 1974) to a participation framework which will best facilitate the confessional narrative of the suspect. However this realignment is itself problematised by some police participants as, through their negotiation of the shift, they must routinely maintain their role as 'interrogator'.
\end{abstract}

\section{Introduction}

In order to address some broader interactional issues, data from three police interviews with suspects from rural south-east Australia are analysed and some features of the interviews are considered in terms of the police strategies they expose and how this relates to the achievement of the institutional goals of the interview. Firstly, the structure of the interviews will be considered in terms of Goffman's participation frameworks and participant roles. Following this, a language-based tri-partite structural framework will be proposed. We will then see how this structural analysis can inform a discussion about police strategies used to elicit a confession from suspects. 


\section{Participation frameworks and institutional goals: A structure for the Interviews}

\subsection{Goffman's participant roles}

Goffman's participation frameworks (Goffman, 1974) are a way of describing spoken discourse in terms of the roles occupied by the participants (both speaker and listener/s) and how these roles (principal, author, animator and figure) are defined by the speaker's 'attitude' or orientation to the content of the utterances which comprise the discourse. The speaker is assigned the role of author if s/he has selected the words which express the sentiment of the utterance and arranged them appropriately. The speaker is assigned the role of principal if $\mathrm{s} / \mathrm{he}$ is responsible for the sentiments so expressed, and for any consequences arising from the expression of the sentiments. The role of animator is assigned to the person who physically produces the utterance and the role of figure is assigned to one being spoken of. The distribution of the roles amongst the participants is known as the participation framework.

Participation frameworks and participant roles provide the tool for analysis which will enable us to identify the discursive structure of a police interview. The parts so identified can then be considered in terms of the goals of the police participants - goals which are defined in Victoria, Australia by the police institution through the Standing Orders and the Crimes Act and it can be determined that discursive structure can be aligned with a goal-based structure.

\subsection{The Opening and Closing}

The opening and closing of the police interview can be defined with reference to the institutional goals of the interview fairly simply due to the known police regulatory requirements. Both the opening and closing sections of the interview are used to inform suspects of their rights and obligations and to carry out certain administrational tasks, such as obtaining the personal details of the suspect for official police records and laying formal charges.

For instance, the Victorian Crimes Act 1958 states in Section 464A(3):

Before any questioning (other than a request for the person's name and address) or investigation under sub-section (2) commences, an investigating official must inform the person in custody that he or she does not have to say or do anything but that anything the person does say or do may be given in evidence. 
The precision of the opening and closing in institutional terms is safeguarded by providing police officers with training and interview aids, such as written forms that guide them through the requisite utterances and are filled out with the suspect's responses as appropriate.

In examining the data it was found that each interview, though separated by as much as three years, contained a formulaic set of utterances in the opening and closing and these utterances were labelled 'Formal Statements'. This examination of the data showed that, in the Opening of each interview, there were no turns taken by the primary interviewing officer that did not form part of a Formal Statement. That is, each interviewing officer starts with the same Statement and works through the same set of Statements until she or he is finished. The analysis of the Closing of each interview indicated a similar discursive arrangement, although the insertion of clarification sequences does change the surface appearance of the three Closings. Notwithstanding these clarifications and a slight variation in Interview $1^{\mathrm{i}}$, the sets of Formal Statements used in the Opening and Closing are remarkably consistent across all three interviews and it would be difficult to argue that the police interviewers are producing the talk spontaneously. Obviously, they are reading from a type of script (possibly one they have memorised), and in fact some of the statements have as a feature reference to their own obligatory nature (e.g. POL2/16: I must inform you that...).

\subsubsection{Participant roles in the Formal Statements}

Heydon, 1997 finds that where police officers are using official police statements, they cannot be said to be responsible for 'writing' the utterance nor for the decision to produce it, or to produce it at a particular stage in the interview. Thus it can be argued that at such times, the participant role of the police officers themselves reflects their institutional role of acting only as representatives of the police force as a whole. That is, the participant roles (Goffman, 1974) of author and principal are assigned to the police institution, rather than to the police officer as an individual. The role of animator is assigned to the police officer though, which would make him or her responsible for speech errors.

This arrangement is true of the data examined in this study as well. The statements identified conform to the definition of 'formal police statement' in the sense that, as discussed, they are individually scripted, and their sequence predetermined, by the police institution. Thus in this set of interview data, the participation framework of the Opening and Closing can be described as one in which the police officer is assigned the role of animator but the roles of principal and author are assigned to the police institution, and this framework is recognised by the participants and displayed in their turn structure. 


\subsubsection{Achieving institutionally defined goals}

The institutionally defined goals of the Opening and Closing can be described as the things that the institution prioritises in these parts of the interview. Police regulations ensure that certain legislative requirements are met when police officers carry out interviews and the adherence to the regulations is therefore a priority for the institution if the legislative requirements are to be fulfilled. This has a large impact on language use in the Opening and Closing of police interviews because the regulations stipulate what must be said by the interviewing officer and in fact provide a script for the officer. Note too that the required script is not assigned to an individual, but to an institutional role.

As mentioned above, the participation framework invoked in the Opening and Closing of the interviews by the police officers is one which assigns the roles of author and principal to the police institution and only the role of animator to the police officer. This distribution of roles will be assigned the code PI2R, which indicates that the Police (P) Institution (I) is assigned two roles (2R), namely author and principal (see Appendix II for a list of abbreviations used in this paper). We have noted that this is a participation framework recognised by the police participants and overtly expressed in various utterances which take the form of I must inform you. Incidentally, the analysis of data from the Closing segments demonstrated an unwillingness on the part of the police officers to deviate from the actual terminology provided by the institutional script when they had to explain a phrase or concept, although it was noted that some less formal or institutional structures were employed by officers in this situation (Heydon, 2002).

When we consider the institutional goal of achieving a high level of conformity to the regulation script, which is intended to ensure that the legislative requirements have been fulfilled, then we can appreciate that the participation framework that is invoked by police officers assists in the achievement of the institutionally defined goals. The individual officer who relegates to the institution the authorship of and responsibility (principalship) for the words she or he utters is reducing the possibility of deviating from the police regulations outlined in the Standing Orders. On the other hand, if officers were to rely on their own judgement of which words best fulfilled the police regulations, they would run a great risk of getting it wrong. As interviews are tape recorded and used by the defendant and their legal representative to prepare their court case, the risk of any error being detected and the interview evidence being disregarded is very high. The use of a script, written or memorised, and the participation framework this invokes, is therefore more than a mere convenience: it provides interviewing officers with a reasonably reliable mechanism for producing interviews which adhere to the relevant Standing Orders. 
Thus, the requirements dictated by the institutionally-defined goals that provide functional parameters for the Opening and the Closing are aligned with the language use in the same parts of the interview in such a way that the Opening and the Closing can be meaningfully referred to as discreet parts of the interview's discursive structure. In short, we can be comfortable about using the terms Opening and Closing to describe the first and last parts of the interview because they are parts that are marked by the participants in their language use and recognised by the institution for their functionality.

\subsection{Information Gathering}

When considering the assignment of roles in the remainder of the interview, it might be useful to consider an ideal situation, a participation framework that would conform to a police bestcase scenario. We know that the most successful evidentiary interview with a suspect is one in which the suspect is shown to be guilty (Settle, 1990) because ultimately in court this will support the police decision to use state resources in making the arrest. Further, we know that the best kind of revelation of guilt is a confession by the suspect (Shuy, 1998) and that such a confession will be most effective, useful and believable if it is produced spontaneously by the suspect with no prompting or leading by the interviewers (Shuy, 1998). We might imagine the perfect interview, from a police perspective, to consist of the formal police statements at the beginning and end, and a suspect-produced monologue forming a confession in the middle. Although this is obviously an oversimplified ideal, it serves to illustrate an important point: for any confession that may be embedded in a suspect's utterances to be used to convict the defendant in court, it must not be seen to be the product of police influence through suggestion or coercion in the interview (or outside it, for that matter). The effect this has on interview procedure is to produce an awareness in police officers that it is always going to be best if suspects tell their story in their own words. If the entire middle section of the interview consists of spontaneous talk by the suspect, then there is absolutely no danger of any confession contained therein being dismissed in court as 'forced' or illegitimately obtained.

We can therefore speculate that the ideal participation framework for the middle stage of an interview would be one where the suspect is assigned the role of animator, author and principal: she or he is responsible for the production of the utterances (animator), the writing of the words spoken and their meaning (author) and the consequences of the utterances (principal). By contrast, the police interviewer would, ideally, be assigned none of these roles for the duration of the information gathering phase and furthermore the importance of maintaining this participation framework would be considered by the police officer to be paramount to obtaining a conviction in court when a confession from the defendant is a key piece of evidence. 


\subsubsection{The Information Gathering}

Extracts from the middle section of each of the interviews can be used not only to demonstrate the participation frameworks invoked by the participants, but also to show how certain participation frameworks are preferred by the police participants. We are able to observe the police participants displaying their alignment to a certain participation framework through their display of knowledge. There are several instances in the data where the police participants are forced to negotiate the 'ownership' of information in an effort to maintain a certain participation framework. On these occasions, the requests for information made by the police participants are made not because the police do not know the answer to the question, but because they want the suspect to answer the question on record, as though he (the suspect) is the owner of the 'new' information. However, in the cases examined, various complications cause the police participants to reveal to the other participants that they in fact are already in possession of this knowledge.

If we take the following extract as an example, we can see this process in operation. In this interview, the suspect, SUS1, is being questioned about an assault that took place in a shop where 'Betty', the suspect's ex-partner, works. 'Ian' is the victim of the assault.

\section{Extract 2-1}

207. POL1: can you just explain to us who Ian is (.) like

208. SUS1: (0.4) I don't know him

((Ten lines of discussion of Ian's role at the shop omitted))

218. POL1: but he serves at the counter and stuff doesn't he

219. SUS1: yeah just helps out a bit there

220. POL1: he assists: the sales

221. all right so it's Ian Flemmings

222. SUS1: (0.6) I- I don't know him

223. I honestly don't know him

224. POL1: right

225. SUS1: I don't know (where he comes from or)

226. POL1: his name's Ian Flemmings

$227 . \quad$ you only know him as Ian

228. SUS1: that's it

This extract demonstrates the way in which the participation framework proposed as an ideal in section 2.3 is treated by the interviewing officer as the preferred structure in the elicitation of information from the suspect. We see in line 209/POL1: can you just explain to us who 
Ian is like, that in establishing the identity of Ian, the interviewing officer first attempts to elicit the information from SUS1. This proves a little fruitless as SUS1 claims not to know Ian, although it is fascinating what this segment tells us about how we define 'knowing somebody' - in practical terms, for SUS1 at least, I don't know him means perhaps that he is not a friend of SUS1's and he doesn't know his full name. ${ }^{\text {ii }}$ Clearly Ian is not a stranger to SUS1.

Following this, POL1 makes some suggestions to SUS1 about Betty's relationship to Ian (lines omitted from Extract 2-1) and about what Ian's role at the shop might be which SUS1 comments on and revises to some extent. Finally in line 223 POL1 states: all right so it's Ian Flemmings to which SUS1 continues to respond that he doesn't know him.

What is so revealing about this segment is the fact that although POL1 had quite a store of knowledge about Ian, she only revealed this information when she failed to elicit it from SUS1. For instance, all present in the interview know that Ian is the victim of the assault allegedly perpetrated by SUS1, and they are all aware that they all know this. They even display this in their use of language by introducing Ian as a known figure earlier in the interview, in lines 190 and 201. No explanation for his appearance in the narrative is offered by SUS1, who introduces him in line 190, or requested by POL1, who asks two questions in lines 201 and 203 about Ian's possible involvement in making a threatening phone call to SUS1. That is, the segment and the elicitation attempts had little to do with POL1's need to attain further knowledge about Ian, but were intended to provoke a display of this knowledge by SUS1. SUS1 was also an active participant in this struggle - his claim that he didn't know Ian stands in contrast to his ability to display quite a lot of information about him and, indeed, his spontaneous mention of Ian in the first place.

We can see then, that POL1 is keen to invoke a participation framework in this segment where the roles of author and principal, together with the role of animator are assigned to SUS1 for the display of knowledge about Ian. She can only ask questions to which she is known to have the answer if she assumes only the role of animator herself and assigns the principal and author roles to the police institution. That is, as an individual, even as an individual police officer, she is known by the other participants to 'own' certain knowledge about Ian and it would not be appropriate for her to take author- and principalship of utterances which contradict her knowledge state - i.e. utterances which request information about Ian's identity. The police institution, on the other hand, may ask these questions in order that the information be supplied 'on record'. It might be helpful to imagine the speaker role that is preferred by POL1 here as being one which allows her to ask questions 'on behalf of' the police institution, which she could not sensibly or logically ask herself. 
The analysis of Extract 2-1 from Interview1 clearly demonstrates that the participation framework that was proposed above as an ideal for the elicitation of information from suspects is deliberately invoked by POL1 such that her preference for this framework is displayed. Similar analyses of data from Interview2 and Interview3 confirm that this police behaviour is common to all three interviews. However, what is so very interesting here is that the behaviour of SUS1 is not unique either - there are several similar instances in Interview2 and Interview 3 where the suspects demonstrate that their priority is to produce a consistent narrative, irrespective of claims made or evidence produced by the interviewing officers. The example from Interview1 that we have seen in Extract 2-1 above involved POL1's request that SUS1 identify Ian, the victim of the assault. SUS1 avoids complying with the request by claiming not to know Ian. ${ }^{\text {iii }}$ SUS1 then continues to claim that he does not know Ian, even though he has already described seeking Ian out and blaming him for the threatening phone calls he received. In other words, having made a claim, SUS1 then ensures that he avoids contradicting this version of events, no matter how difficult that becomes.

To take just one further example, in Interview2, relating to an assault charge on the suspect's girlfriend, 'Leila', the suspect is asked to identify which of Leila's arms he had held during the incident. As can be seen in the following extract, this results in SUS2 producing the preferred response 'the right one'. That is, the question asked by the interviewing officer, POL2, contains an underlying assumption that only one arm was held by SUS2 so to respond 'both arms' would challenge this underlying assumption and thus be dispreferred (Bilmes, 1988; Sacks, 1987).

\section{Extract 2-2}

230. POL2: all right well when you had hold of her bicep

231. (.) which (0.2) arm was that do you remember

232. SUS2: (0.4) yip

233. POL2: (0.4) which one

234. SUS2: (0.2) right one

235. POL2: (0.2) a::hm at some stage

236. didja have ever have hold of 'er other arm

237. (0.6) bicep

238. SUS2: (1.0) no I (0.4) no

239. POL2: a::hm (2.0) it's a::h (.) she's had (.) some injuries on 'er arm

240. (0.2) bruising to bo:th (.) biceps

241. SUS2: $\mathrm{mm} \mathrm{hm}$

242. POL2: at some stage (0.2) didju have hold of 'er other bicep

$243 . \quad$ (.) dragging her outside

244. ((sound of door closing or seat moving)) 
245. SUS2: (1.4) not that I can remember

246. POL2: so you can't explain how those (.) marks would 'ave got there

247. SUS2: (0.4) the one on the right (.) arm would have been from me grabbin a (.) but

248. POL2: right (4.4) and OK u:m

249. (1.0) after the second (0.2) time you've (0.2) grabbed a

250. (0.6) you went back inside

251. what happened then

Since SUS2 has no reason to admit spontaneously to causing more damage than POL2 is suggesting he might have caused, the request is hardly likely to result in an elicitation of SUS2's confession to causing injuries to both of Leila's arms. Hence POL2's resulting dilemma: through the wording of his question he has now put himself in a position where the elicitation of a further confession will require SUS2 to contradict what he has just said. That is, POL2 now needs SUS2 to say that he held not just the right arm, but the left arm as well. It is extremely interesting to note what happens next. POL2 moves to his next, less preferred, option for eliciting the confession: he reveals ownership of certain knowledge he has previously withheld (much as POL1 did in Extract 2-1 above) in a bid to force SUS2 to confess to causing injury to Leila's left arm as well. He reveals that he in fact knows of injuries to Leila's left arm and then asks SUS2 a question which would require him to revise his prior description of his actions: 242/POL2: at some stage (0.2) didju have hold of er other bicep. SUS2, however, declines the invitation to contradict himself, even in the face of POL2's (fairly strong) evidence in favour of a revision of his earlier statement. That is, the suspect in this instance chooses to contradict the police officer, and the physical evidence POL2 brings to bear, in preference to contradicting his own story. Given the suspect's commitment to the consistency of his own version of events, the interviewing officer would have done well to phrase his original question more carefully.

In each of these cases, and in other cases analysed in Heydon 2002, this type of suspect behaviour results in the interviewing officers having to reveal knowledge previously withheld and thus align with a participation framework in which they assume the roles of animator, author and principal in relation to their utterances. It appears that this participation framework is invoked in response to a conflict between the suspect's narrative and the evidence already accumulated by the police, but it is not a participation framework which is preferred as a starting point to the elicitation of a confession.

The analysis of extracts from the information gathering parts of the interviews reveal that while our prediction of a particular participation framework (where the suspect occupies the roles of animator, author and principal) being preferred by police remains accurate, we can 
identify a second participation framework (where the interviewing officer occupies the roles of animator, author and principal) which is invoked when the responses of the suspect do not match the police knowledge or evidence of events. These two participation frameworks can be labelled S3R (suspect occupies the three roles of animator, author and principal) and P3R (police officer occupies the three roles of animator, author and principal) The analysis suggests that P3R is a dispreferred option for the police officer, not only because it is used when the alternative, S3R, fails, but because it does not necessarily result in agreement between the two versions. In fact, in each of the extracts analysed (see also Heydon 2002: 828), the alignment to P3R resulted in the interviewing officer having to abandon the line of questioning altogether and in doing so admit the extent of the police knowledge of that part of the narrative (the full name and role of Ian in Interview1 and the bruising to Leila's arms in Interview2). Clearly it is undermining the voluntary nature of the confession if parts of the narrative have to be supplied by the interviewing officer.

\subsubsection{Achieving institutionally defined goals}

The analysis in section 2.3.1 above clearly demonstrates that in terms of the discursive structure and the participants' orientation to their version of events, there is a constant attempt by both parties to achieve the same alignment to information that they present. This alignment can be represented as the participation framework labelled S3R. Although it may not seem immediately apparent that this is always the case, in Heydon, 2002 I find through detailed analysis of the data that the behaviour of the police officers strongly supports their preference for a participation framework where the suspect takes up the roles of author, animator and principal of any part of the evidence. As for the suspects, they too display a strong preference for the S3R framework, but only in relation to information that aligns with their version of events. We noted in relation to extracts from Interview 1 and Interview2 that when the interviewing officer presented information which conflicted with their version of events, the suspects chose not to contradict their own story, despite strong evidence presented by the police officers. Thus it can be said that both the suspect and the police officer are maintaining consistent preferences for participation frameworks throughout the Information Gathering.

If we consider the institutionally-defined goals of the interview in this section we can see that there is an alignment between the consistency of the participation frameworks and the key institutional requirements. As discussed in section 2.3, the over-riding police institutionallydefined goal for the information gathering is to provide a forum in which the suspect will produce a voluntary confession. In terms of participation frameworks, this would mean maintaining an S3R framework throughout the information gathering, since any part of this section can form part of the suspect's confession, and should ideally be elicited within the 
S3R framework. Therefore, the fact that we have found a consistency in the discourse of all participants in terms of their orientation to particular participation frameworks correlates directly with the key functional requirement of the Information Gathering: to achieve the goal of a voluntary confession. It is therefore possible to consider the Information Gathering as a discreet part of the interview, having distinct linguistic features which not only delineate it from the surrounding talk, but which are aligned with the particular functional requirements of this section.

\subsection{A discursive, goal-oriented structure of the police interview}

The preceding analysis revealed an alignment between institutionally-defined goals and participation frameworks invoked by participants in the three police interviews. The importance of these findings is that it allows us to describe the structure of interviews in terms of the participants' language use, knowing that this discursive description reflects the functional requirements of the interview as prescribed by the institutions governing the interview (i.e. legislation and police regulations).

A structural framework can now be proposed which is both oriented to by participants, as evidenced in their invocation of particular participation frameworks, and valid in terms of the institutional goals. This framework is represented in Table 1:

Table 1 Goals and participation frameworks in the tri-partite interview framework

\begin{tabular}{|l|l|l|l|l|}
\hline \multirow{2}{*}{ Goal } & \multicolumn{2}{|l|}{ Primary or Target Participation Framework } & \multirow{2}{*}{ Structural frame } \\
\cline { 2 - 3 } $\begin{array}{l}\text { Adhere to police } \\
\text { Standing Orders }\end{array}$ & $\begin{array}{l}\text { Author } \\
\text { Police } \\
\text { institution }\end{array}$ & $\begin{array}{l}\text { Principal } \\
\text { Police } \\
\text { institution }\end{array}$ & $\begin{array}{l}\text { Animator } \\
\text { Primary } \\
\text { Interviewing } \\
\text { Officer }\end{array}$ & OPENING and \\
CLOSING \\
$\begin{array}{l}\text { Produce voluntary } \\
\text { confession }\end{array}$ & Suspect & Suspect & Suspect & $\begin{array}{l}\text { INFORMATION } \\
\text { GATHERING }\end{array}$ \\
\hline
\end{tabular}

Table 1 illustrates the relationship between the discourse structure of the interview, identified as participation frameworks, and the key institutionally-defined goals of the participants. The resulting tri-partite framework (Opening, Information Gathering and Closing), can now provide a valid basis for further linguistic analysis of the participant negotiation of shifts between parts of the interview and participant achievement of interview goals. 


\section{Achieving shift into S3R}

The establishment of a tripartite interview framework implies that the participants must attempt a shift in the distribution of participant roles as they move into the Information Gathering if they are to fulfil the functional requirements of the interview. This shift from the Opening to the Information Gathering can be described in participant role terms as a shift from a PI2R framework to an S3R framework and in this section the relevant parts of the interview data are examined with the aim of describing the negotiation of this shift in roles. The intention of the analysis is to describe how police discursive behaviour in the initiation of the shift to the Information Gathering may affect the uptake of the S3R framework by suspects.

\subsection{Producing the turns which signal shift}

Each of the interviews contains a turn that serves to mark the end of the Opening: the point after which the interviewing officers must negotiate the commencement of the Information Gathering. In the case of Interview3, which concerns offenses relating to the cultivation of marijuana, SUS3 responds to POL3's request for a version of the day's events with a turn represented by line 73/SUS3: (0.4) jus' pulled em out and (.) took em away. This description, referring to the removal of marijuana plants from the suspect's house, is restricted to a very small portion of the day's events. It also lacks any details about the actions that it does mention: even the agent is lacking and at this point the uninformed listener cannot say whether the actions were executed by the speaker or the police officers mentioned by POL3 in line 71. Given that the description of pulling the plants up and taking them away is substantive, new (in the context of the interview) information and results from an open question, it is clear that SUS3 is taking up the roles of principal, author and animator in relation to the content of his utterance. However, the S3R framework is not maintained by SUS3 - that is, he does not continue to offer new information or to expand on the information already given. Extract 3-1 below takes up Interview3 from SUS3's line 73.

\section{Extract 3-1}

73. SUS3: (0.4) jus' pulled em out and (.) took em away

74. POL3 (1.0) OK (1.4) ah (0.4) when you say you pulled em out

$75 . \quad(0.2)$ ah do agree that a:h (0.2) you pulled out seventeen $(0.4)$ ah

76. SUS3: yes

77. POL3 various sized (0.2) marijuana plants

78. SUS3: yes

79. POL3 (0.4) ah (.) and where were they

80. SUS3: (0.5) in the fernery 
81. POL3 (1.2) OK (0.6) and ah (.) whose were they

We see that a one second silence follows line 73, perhaps indicating that POL3 is awaiting further comment by SUS3, although it may be because POL3 is making notes. In any case, SUS3 does not choose to volunteer further information but rather waits for POL3 to take the next turn. In fact, in this part of the interview, SUS3 never takes up the opportunity to add further information when a silence develops between the speakers, as we can see in line 74, where a 1.4 second silence follows POL3's $O K$ and in line 81 where a 1.2 second silence follows line 80/SUS3: (0.5) in the fernery. In both these cases, as in the one discussed above, it is POL3 who breaks the silence.

In Extract 3-1 we see SUS3 agreeing readily to information presented by POL3 in lines 75 to 78. SUS3 utters an affirmative yes twice in response to POL3's request for agreement. The first time he does not even wait for POL3 to complete the assertion to which he is agreeing but rather inserts his agreement into a very short silence in POL3's turn. This is indicated by the latching between the end of POL3's line 75 and SUS3's line 76 and then line 76 and POL3's line 77.

We can see, therefore, that while SUS3 has shown that he is unwilling to invoke the S3R framework, he is willing to agree to the validity of statements he has not authored or animated. We might propose that this constitutes a new framework where the police officer is author and animator of the utterance but the suspect agrees to take up the role of principal in relation to it. We can label this participation framework P2RA. This label indicates that the Police officer (P) occupies the two roles (2R) of author and animator (A). The invocation of the P2RA framework indicates that the suspect, SUS3, is not unwilling to disclose his knowledge of certain events. In fact, the latching in lines 75 to 78 (see Extract 3-1 above) indicates that SUS3 is very prompt in his agreement to the allegations made by POL3. However, SUS3 continues to display an unwillingness to volunteer information in the form of a narrative, or to make statements about the events that are not in direct response to a question.

We might now compare this behaviour with that of SUS1 and SUS2. POL1 focuses the final stages of her transitional utterances on the location of the incident. She has mentioned the Littlevillage takeaway shop as the place where the incident occurred, and SUS1 responded with a confirmation 45/SUS1: right. Extract 3-2 below picks up Interview1 at this point and we can see how the participants move towards the Information Gathering.

\section{Extract 3-2}


46. POL1: you know the shop

47. SUS1: yes

48. POL1: what sort of connection do you have to the shop

49. SUS1: (1.7) nothin Betty and I we've

$50 . \quad(0.2)$ aw we've been together for nine years de facto relationship we-

51. POL1: w'l who's Betty

52. SUS1: (0.5) Fisher

53. POL1: (0.6) yeah

54. SUS1: and

55. POL1: what she owns the shop does she

56. SUS1: no her brother owns the shop she only runs it

In the section of the interview immediately following the transitional utterances, POL1 asks for SUS1's confirmation that he knows the shop she has mentioned and then uses the shop as the focus of her first request for substantive information in line 48/POL1: what sort of connection do you have to the shop. Following an initial rejection of any connection (nothin ), SUS1, without any further prompting, begins to describe his relationship to a pivotal character in the day's events, Betty, his ex-de facto wife. This swift uptake of the S3R framework by SUS1 is halted by POL1 who interrupts SUS1 to ask in line 51/POL1: w'l who's Betty. SUS1 responds with Betty's surname and seems about to resume his narrative in line 54/SUS1 and, when POL1 interrupts with a request for further clarification 55/POL1: what she owns the shop does she. Following this second interruption, SUS1 ceases to attempt to add information using the S3R framework. He responds to the clarification with an explanation of Betty's relationship to the shop but does not offer any further information about Betty or attempt to restart his narrative about their de facto relationship. SUS1 does eventually 're-invoke' the S3R framework, however. After a number of turns in a questionanswer framework - one we might describe as a P2RA framework (see above) - the following exchange takes place.

\section{Extract 3-3}

68. POL1: (0.5) right (1.9) w'1 (0.8) y' how co- can you start Friday

$69 . \quad$ what di- $(0.3)$ what started $(0.4)$ on Friday

70. SUS1: well (0.3) what started Friday was Friday morning when I received a phone call

71. (1.6) $\mathrm{n}$ that was around ten $\wedge(0.2)$ yeah $(0.4)$ ten to ten thirty

$72 . \quad$ cause it was $(0.4)$ not far after the news

73. (1.3) so I picked it up answered and they said

74. (0.3) Joh- ah Johnny $\Rightarrow$ Johnny 
$76 . \quad$ (1.2) they said right if you go anywhere near the shop

$77 . \quad(0.6)$ or any where near the house

$78 . \quad(0.8)$ you're going to get your legs broken

$79 . \quad(1.1)$ and that was it

80. $\quad(0.2)$ just hanged up

By repeating POL1's question as the first part of his response 70/SUS1: well (0.3) what started Friday was Friday morning SUS1 frames his turn as directly relevant to POL1's request and presents himself as a co-operative respondent. However, SUS1's narrative detail stops a long way short of describing the incident about which he is being interviewed. So although SUS1 is willing to co-operate and provide new information in 'his own words' - that is, he is willing to invoke the S3R framework - he does so strictly with the boundaries of POL1's request. She asked him what started (0.4) on Friday in line 69 and he responded with a description of the first relevant event on Friday morning: a threatening phone call he received. His turn finished when he finished describing that event.

If we now compare this to a similar point in Interview2, we can see a different approach being taken to the alignment with an S3R framework by the participants. Extract 3-4 picks up the interview where SUS2 is confirming the point of departure for his trip to Bigtown, where the incident took place.

\section{Extract 3-4}

38. SUS2: Satellite River (.) L- (.) Leila's place in Satellite River

39. POL2: right

40. SUS2: (1.0) went to a f:::friend of mine's in:: (0.2) Bigtown

41. POL2: do you know the address of that house

42. SUS2: Spray Street I think

43. POL2: don't know the number

44. SUS2: no:: $(0.2)$ it's behind $3 Z X^{\text {iv }}$

45. POL2 rih

46. SUS2 that's (3.0) not sure if its there $\Rightarrow$ or $u^{\prime} \mathrm{hm}$

47. POL2: yeh no that's OKyep

48. SUS2: (0.8) um got there

49. I'm not sure a' what time it was probably about (0.6) in between eight n' eight-thirty

50. 'cause I work that day n' I finished at seven

51. (1.2) um (0.8) got there (0.6) had a few drinks with them 
52.

(0.4) him and Leila had a few (0.4) smokes

53. POL2 (1.0) (h) $\mathrm{m}(\mathrm{h})$

Like SUS1 in Extract 3-3 above, SUS2 seems willing to align with the S3R framework immediately and with no additional prompting in line 40 but does not get much further than one line of narrative before being interrupted for a clarification by the interviewing officer. The following six turns (lines 42 to 47 ) all concern the clarification of the address of SUS2's destination in Bigtown. However, in the case of Interview2, this sequence of turns providing details inserted into the suspect's narrative does not cause any further delay to SUS2's reinvocation of the S3R framework. As soon as POL2 has indicated that SUS2 has given sufficient information (47/POL2: yeh no that's OK yep), SUS2 restarts his description of events. This is a detailed description compared to that offered by SUS3, for instance. Whereas SUS3 chose to reduce the events of the day to two, agentless actions -73/SUS3: (0.4) jus' pulled em out and (.) took em away - SUS2 seems to do the opposite, expanding his description by inserting a mention that he worked that day and what time he finished to account for the time of his arrival in Bigtown. (It is interesting to note that SUS1 engages in the same activity in line 72 , inserting a mention of the news programme to account for the time that he claims the phone call took place.) SUS2 even goes so far as to mention in line 52 that he and his friends had a few (0.4) smokes, which is most likely to mean that they smoked marijuana, particularly given the immediately prior mention of a related activity ( $h a d$ a few drinks with them). ${ }^{\mathrm{v}}$

Thus, not only is SUS2 willing to invoke the S3R framework and make a substantial voluntary confession within that framework, but he is also willing to reinvoke it when he is interrupted without any overt request to do so. This stands in marked contrast to the situation in Interview3 where SUS3 invokes the S3R framework to convey a minimal amount of information and then responds only within a P2RA framework for most of the remainder of the interview. In Interview1, the situation is slightly different again as SUS1 seemed willing to invoke the S3R framework at the earliest opportunity, but then changed his approach to respond within the P2RA framework before taking up his narrative again in a restricted S3R framework.

\subsection{Achieving frame shift}

The above analysis indicates that the success of the frame shift between the Opening and the Information Gathering varies considerably from one interview to the next. In Interview1, the analysis shows us that a clear change in the discursive behaviour of SUS1 takes place after POL1 interrupts him to request clarification about Betty's identity. This contrasts with the 
findings above concerning Interview2 and Interview3 where the discursive behaviour of the suspects and their alignment with the S3R participation framework, whilst different in both cases, does not change once the transitional utterances are completed and the Information Gathering has commenced.

If we now consider the way in which this frame transition was initiated by the police officers we find that Interview2 and Interview3 have in common a feature which is lacking in Interview1: both of the primary interviewing officers in Interview2 and Interview3 clearly state their intentions with respect to their role in the Information Gathering and they both do so as a way of initiating the frame transitional utterance. Extract 3-5 below takes up Interview2 from the question/answer sequence prior to the transition out of the Opening.

\section{Extract 3-5}

25. POL2: do you wish to exercise any of these rights before the interview proceeds

26. SUS2: no

27. POL2: (1.0) awrigh' Charles on um

$28 . \quad(0.4)$ if $y^{\prime} c^{\prime}$ jus tell me in your own words

29. there's an incident wuz: ah reported to me on New Year's Day this year

In line 27 we can see that POL2 may have been about to begin the final request turn of the Opening with the institutionally required mention of the date and location of the incident 27/POL2: (1.0) awrigh' Charles on um. But he does not complete this utterance, and instead produces an utterance in which he positions himself as the recipient of SUS2's own 'telling' 28/POL2: (0.4) if y' c' jus tell me in your own words before proceeding with the institutional part of the turn.

Similarly, Extract 3-6 below, demonstrates that after completion of the penultimate question/answer pair of the Opening in Interview3 (lines 35-38), POL3 begins the final request turn with a clear indication of his intentions.

\section{Extract 3-6}

35. POL3 do you agree that a::h (0.5) you've a::h

$36 . \quad$ spoken to your ah girlfriend or de facto

37. and that you've also spoken to a solicitor

38. SUS3: yes

39. POL3 (0.3) a::h ((creaky voice)) right (3.7)

40. w'l as I said wanna ask you some questions

41. in relation to ay a search warrant 
In line 40, POL3 unequivocally states 40/POL3: w'l as I said wanna ask you some questions before completing the institutional requirement of the Formal Statement. In both cases, these intentions are realised: POL2 does indeed take up the role of 'telling-recipient', despite initiating several clarification sequences during SUS2's telling, and POL3, as we have noted, finds himself asking SUS3 questions or otherwise making requests for confirmation or information for the remainder of the interview.

In contrast to these two cases, POL1 does not make a clear statement regarding her intended role in the interview.

\section{Extract 3-7}

38. POL1: (0.4) r't do you wish to exercise any of these other rights

39. SUS1: no I don't

40. POL1: (0.5) r’t (2.2) .hh a- going back to Friday night

41. $\quad$ hh the thirtieth of June ninety-five

42. (0.7) um an incident which occurred in Littlevillage

43. (1.1) first of all we'll start um

44. (0.4) well the incident occurred at the Littlevillage takeaway shop

The extract above picks up Interview1 at the same point as the previous two extracts - just prior to the final turn of the Opening. There are two places in POL1's formulation of the Formal Statement that give some indication of POL1's intentions. In line 40, the mention of going back to Friday night may refer to 'casting one's mind back' prior to delivering a narrative and in line 43/POL1: first of all we'll start um there is an implication of starting a new phase of the interview.

The only mention by POL1 of her intentions in the interview is much earlier in line 21/POL1: $\mathrm{hm}$ I'm now going to ask you some questions in relation to an incident, which forms part of a previous question/answer pair. The same type of pair is realised in Interview2 as 13/POL2: (1.2) I intend to interv' you in relation to: (.) an assault that occurred in Bigtown (.) and in Interview3 as 20/POL3: (0.6) Leigh I intend to interview: in relation to ah (0.4) some drug offences. These earlier statements would appear to have much less bearing on the discursive behaviour of the suspects in the Information Gathering since SUS2 and SUS3, who receive almost the same wording at this point, behave so differently following the shift into the Information Gathering. In any case, if POL1's statement in line 21 that she intended to ask questions to obtain information had an effect on SUS1's behaviour, it is not apparent in his response to POL1's first request for substantive information (line 48/POL1: what sort of 
connection do you have to the shop) where he almost immediately begins to produce an unprompted narrative. That is, SUS1 begins to behave in way other than that of a 'respondent' - he begins to behave as an initiator of talk.

It is evident, therefore, that a part of the interview which may be critical in determining the participant role alignment in the Information Gathering is the transitional police turn moving the interview out of the Opening and, specifically, the explication by the police officer of the two main participants' discursive roles in the Information Gathering. Where a clear statement of intention was made, the suspect's discursive behaviour in the Information Gathering matched the stated intentions of the police officer at that point. In Interview1, where no clear indication was given by POL1 in the final Formal Statement of the Opening, the suspect began the Information Gathering by strongly aligning to the S3R framework, but then this alignment was weakened considerably following a series of clarification sequences inserted by POL1 into SUS1's description of events.

A similar disruption to SUS2's narrative caused no such change in his alignment to the S3R framework in the Information Gathering, though it should be noted that the clarification sequences initiated by POL1 constituted actual interruptions of SUS1's turns whereas POL2 chose transition relevance places to initiate his clarification sequences.

\subsection{Summary}

This part of the analysis has found that each of the interviewers used a slightly different approach when producing the turn that initiates the shift into the Information Gathering. These slight differences could be seen to account for the various levels of commitment to the S3R framework displayed by the suspects as they began to respond to requests in the Information Gathering.

Broadly speaking, we found that SUS1 appears to move from a strong orientation to the S3R framework to a greatly weakened orientation towards S3R and a stronger orientation towards P2RA during the first few question-answer pairs of the Information Gathering. We saw that SUS3, having moved (or been moved by POL3) into the P2RA framework as soon as the Information Gathering began did not ever commit to an S3R framework in the interview, despite attempts by POL3 to invoke S3R several turns into the Information Gathering. ${ }^{\mathrm{vi}}$ In contrast, SUS2 aligned with an S3R framework as soon as the Information Gathering began, following POL2's invocation of S3R at the point of transition from the Opening to the Information Gathering. Following this, POL2 had no difficulty at any time re-invoking the S3R framework after segments of P2RA turns. 
A final point which I feel must be made, if only very briefly, is that an unsuccessful shift into the S3R framework is characterised by police attempts to control the suspect's discursive space. For instance, in Interview1, POL1 deliberately undermines the suspect's attempts to begin a spontaneous narrative within the S3R framework by initiating an apparently unnecessary clarification sequence. The more detailed analysis of the interviews in Heydon, 2002 reveals that interviewing officers continue to engage in discursive behaviour that ensures their dominance over the interaction regardless of the threat to the S3R framework. Paradoxically, the same officers repeatedly misrepresent their own knowledge state, as in the cases described in section 2.3 above, in order to invoke the S3R framework during the Information Gathering. This suggests that, although they are aware of the importance of voluntary confessions, they are more concerned with asserting their authority over the suspect, at least at the level of the interaction.

\section{Conclusion}

This paper began with the aim of providing a description of the interview structure which aligns the linguistic features of the discourse with the changing goals of the interview and shows that both are oriented to by participants in their turn-by-turn construction of the interview. The analysis presented here confirms that the Opening and Closing can be considered discreet parts of the interviews as they consist entirely of formulaic police utterances, labelled 'Formal Statements', which elicited heavily constrained suspect responses that are classifiable as non-voluntary. The participation framework invoked by the police interviewers in these parts was unchanging and characterised by the assignation of author and principal roles to the police institution with only the role of animator assigned to the police participant. This is consistent with the key functional requirements of the Opening and Closing, which are identified as maintaining adherence to the police regulatory requirements in order to ensure the validity of any confession elicited from the suspect in the remainder of the interview.

The lengthier analysis of extracts from the middle section of Interview1, and Interview2 reveals that despite the invocation of a number of different participation frameworks, it is still possible to see that the participants consistently oriented to one preferred framework. This is labelled S3R to reflect the assignment to the suspect of the three roles of author, principal and animator. Suspects align with the S3R framework only in relation to utterances which supported their version of events, whereas the police participants attempt to invoke an S3R framework for all utterances concerning the events in question. Nonetheless both approaches, or orientations, are consistent throughout the middle section of each interview and both reflected the key goals of the different participants. It is proposed that the Opening, the Information Gathering and the Closing can be identified as discreet parts of the interview 
oriented to by participants in their construction of the discourse, identifiable to analysts through their linguistic features and reflecting the key goals of the interview in each of the three parts.

Finally, the analysis of the negotiation of frame shift from the Opening to the Information Gathering demonstrates that the construction of the frame transitional utterance may be critical to the successful invocation of an S3R framework. Further research testing this hypothesis on a wide range of police interview data would seem to be a priority. There is not the space here for a lengthy discussion of the impact this may have on police institutional discourse as a whole, however, it is possible to see that the analysis of the interview language within a discourse analysis/linguistic framework suggests a conflict between the institutional goals of the interview, and the strategies employed by individual officers to achieve those goals. That is, the institutional priority of achieving a shift into S3R may be undermined by the actions of interviewing officers, especially those actions that serve to control the discourse space. I believe that such findings will be valuable to law enforcement agencies for the purposes of training officers in their interview practices as well as contributing to the body of academic research on police interviewing. As such, I hope that the analytic framework I have suggested here might be used to further our understanding of the discourse of police interviews by enabling large-scale empirical studies of similar data. 


\section{Appendix I}

\section{Transcription conventions}

The conventions used in the transcription of data for this study are based on those outlined in Levinson, 1983.

\begin{tabular}{|c|c|}
\hline Symbol & Description \\
\hline$(0.6)$ & silence measured in seconds \\
\hline (.) & micro-pause of less than 0.2 seconds \\
\hline WORD & louder than surrounding speech \\
\hline$::$ & the sound is lengthened by one syllable for each colon \\
\hline- & truncated word \\
\hline $\mathrm{h}$ & audible outbreath \\
\hline .h & audible inbreath \\
\hline (h) & explosive aspiration (as in laughter) \\
\hline (word) & uncertain transcription \\
\hline ( ) & incomprehensible utterance, no transcription attempted \\
\hline$(()))$ & transcriber's remarks, including comments on voice quality or non-verbal sounds \\
\hline
\end{tabular}

\section{Appendix II}

\section{Abbreviations}

The table below is intended as a convenient guide to the abbreviations used in the transcriptions and the text. 


\begin{tabular}{|c|c|}
\hline Abbreviation & Description \\
\hline \multicolumn{2}{|r|}{ Data: Interviews and Participants } \\
\hline Interview1 & Interview 1 (assault of man in a shop) \\
\hline SUS1 & Suspect participant in interview 1, Jonathon Young (pseudonym) \\
\hline POL1 & $\begin{array}{l}\text { Primary interviewing officer in interview } 1 \text {, Constable Fisher (pseudonym, } \\
\text { female) }\end{array}$ \\
\hline Interview2 & Interview 2 (assault of suspect's girlfriend) \\
\hline SUS2 & Suspect participant in interview 2, Charles Nielsen (pseudonym) \\
\hline POL2 & $\begin{array}{l}\text { Primary interviewing officer in interview } 2 \text {, Senior Constable Atkins } \\
\text { (pseudonym, male) }\end{array}$ \\
\hline Interview3 & Interview 3 (cultivation of marijuana, possession of firearms) \\
\hline SUS3 & Suspect participant in interview 3, Leigh Ventnor (pseudonym) \\
\hline POL3 & $\begin{array}{l}\text { Primary interviewing officer in interview } 3 \text {, Constable Laurel (pseudonym, } \\
\text { male) }\end{array}$ \\
\hline S3R & $\begin{array}{l}\text { Participation framework where the author, principal and animator roles are } \\
\text { allocated to the suspect }\end{array}$ \\
\hline P3R & $\begin{array}{l}\text { Participation framework where the author, principal and animator roles are } \\
\text { allocated to the police interviewer (primary or secondary) }\end{array}$ \\
\hline PI2R & $\begin{array}{l}\text { Participation framework where the author and principal roles are allocated to } \\
\text { the police institution }\end{array}$ \\
\hline P2RA & $\begin{array}{l}\text { Participation framework where the author and animator roles are allocated to } \\
\text { the police interviewer and the principal role is allocated to the suspect }\end{array}$ \\
\hline
\end{tabular}

\section{Notes}


${ }^{i}$ In Interview1, the police interviewer requests the suspect's occupation, a request that does not appear in Interview2 or Interview3. An analysis of this apparently anomalous request finds that it in in fact consistent with the participation framework of the remainder of the Opening Heydon, 2002.

ii This situation might usefully be compared to the notion of 'knowership' proposed by Goffman, 1983 as involving 'the right and obligation mutually to accept and openly to acknowledge individual identification on all initial occasions of incidentally produced proximity' (p. 13).

iii Unfortunately we are unable to ascertain why SUS1 takes this stance of ignorance - we can only speculate that he must feel it mitigates his actions in some way, perhaps because he is trying to give the impression that the assault was not premeditated - if he did not know Ian, he could not have planned to assault him. Alternatively, SUS1, having recently ended a long-term relationship with Betty, may be unwilling to give any more weight than necessary to the possibility that she has begun a new relationship with Ian. Certainly SUS1 is quick to downgrade Ian's relationship with Betty from 'boyfriend', as suggested by POL1, to 'someone who hangs around the shop' (while still claiming not to know him!) which would support this alternative. Ultimately, though, it may be a combination of these factors, and others, which motivates SUS1 to claim he does not know Ian.

iv SUS2 names a radio station, which is here given the pseudonym 3ZX

${ }^{v}$ Although the term smoke (both in verb and noun form) could refer to marijuana or cigarette smoking, in this part of Australia at least, references to smoking as a social activity imply the consumption of marijuana in the same way that references to having a drink with friends will ordinarily be understood to refer to alcoholic drinks. This is evident in the following utterance as well: 138/SUS2: and I said well $\downarrow$ (0.6) more like you've had too much to $\downarrow$ (0.2) smo:ke^.

vi It should be recognised that SUS3's choice of frame may be a product of differing circumstances, in particular the much greater amount of incriminating evidence gathered by POL3 and sio3, which weakens SUS3's defensive position. 


\section{References}

Bilmes, J. (1988). The concept of preference in conversation analysis. Language in Society, $17,161-181$.

Goffman, E. (1974). Frame Analysis. New York: Harper and Row.

Goffman, E. (1983). The interaction order. American Sociological Review, 48(February), 117.

Heydon, G. (1997). Participation frameworks, discourse features and embedded requests in police V.A.T.E. interviews with children. Unpublished Honours Thesis, Monash University, Melbourne.

Heydon, G. (2002). 'Do you agree that she would have been frightened?': An investigation of discursive practices in police-suspect interviews. Unpublished $\mathrm{PhD}$, Monash University, Melbourne.

Levinson, S. C. (1983). Pragmatics. Cambridge: Cambridge University Press.

Sacks, H. (1987). On the preferences for agreement and contiguity in sequences in conversation. In G. Button \& J. Lee (Eds.), Talk and social organisation (pp. 54-69). Clevedon, Philadelphia: Multilingual Matters Ltd.

Settle, R. (1990). Police power: use and abuse. Northcote: Muxworthy Press.

Shuy, R. W. (1998). The language of confession, interrogation, and deception. Thousand Oaks: Sage. 